\title{
Insights from Stakeholders of Five Residential Smart Grid Pilot Projects in the Netherlands
}

\author{
Uchechi Obinna ${ }^{1,2 *}$, Peter Joore ${ }^{1,2}$, Linda Wauben ${ }^{1,3}$, Angele Reinders ${ }^{1,4}$ \\ ${ }^{1}$ Delft University of Technology, Delft, The Netherlands \\ ${ }^{2} \mathrm{NHL}$ University of Applied Sciences, Leeuwarden, The Netherlands \\ ${ }^{3}$ Rotterdam University of Applied Sciences, Rotterdam, The Netherlands \\ ${ }^{4}$ University of Twente, Enschede, The Netherlands \\ Email: "u.p.obinna@tudelft.nl
}

Received 8 November 2015; accepted 16 January 2016; published 19 January 2016

Copyright (C) 2016 by authors and Scientific Research Publishing Inc.

This work is licensed under the Creative Commons Attribution International License (CC BY).

http://creativecommons.org/licenses/by/4.0/

(c) () D Den Access

\section{Abstract}

This paper presents insights and perceptions of stakeholders involved in the development and implementation of residential smart grid pilot projects in the Netherlands, adding to the limited information that is currently available in this area, while expectations about the potential benefits of smart grids are high. The main research questions of this study are: (1) How have some typical residential smart grid pilots in the Netherlands been set up? (2) Which stakeholders are involved in these pilots in the year 2014? (3) What are their views and perceptions with regards to the development and performance of residential smart grids? and (4) What do these stakeholders think about the products and services that may support an active participation of end-users in a smart energy home? To obtain information, we evaluated five residential smart grid pilot projects where smart energy products and services have been implemented. Semi-structured interviews were conducted with nine stakeholders involved in these projects. The Strategic Niche management framework was used to identify the present state of development and implementation of smart grid pilots. Our study shows that in the Netherlands residential smart grid pilots have been set-up and funded mainly by the government and grid operators. Other stakeholders involved include energy suppliers, end-users (as an energy cooperative or individual household), product and service suppliers, Information and Communication Technology (ICT) companies, and knowledge institutes. Currently a technology-push approach exists which barely includes an integrated approach towards smart grids products and services development. To the opinion of the interviewed stakeholders, current products and services offered in residential smart grid pilots are functionally attractive, but often too technically complex for the understanding of end-users. Hence, the general view held by respondents is that end-users should be the starting point in the develop-

${ }^{*}$ Corresponding author.

How to cite this paper: Obinna, U., Joore, P., Wauben, L. and Reinders, A. (2016) Insights from Stakeholders of Five Residential Smart Grid Pilot Projects in the Netherlands. Smart Grid and Renewable Energy, 7, 1-15.

http://dx.doi.org/10.4236/sgre.2016.71001 
ment of smart grid products and services at the residential areas.

Keywords

Smart Grid, Strategic Niche Management, Products and Services, Stakeholders, Residential Areas, End-User

\section{Introduction}

Our energy provision system is changing by a continued increase in energy demand, scarcity of fossil fuels and calls for climate change mitigation [1]. At the moment a transition is taking place from centralized electricity generation, to more decentralized and flexible electricity generation mainly based on renewable energy sources [2] [3]. Smart grids are considered a promising solution that will support this paradigm shift, and a key to demand and supply-side management of energy systems [4] [5].

In the last few years, smart grid initiatives with various aims and results have been growing in number and scope all over Europe [6]-[9]. In 2014, there have been about 250 smart grid pilot and demonstration projects in Europe [9]. In the Netherlands, an increase in the number of smart grid pilot projects has been witnessed since 2008. Currently, there are about 30 Dutch pilot projects being carried out [6] [10]. More than half of these projects are taking place at the low voltage residential areas [10]. It is assumed that this focus is as a result of increased small-scale distributed energy systems in and around homes and neighborhoods, which are expected to become a common feature in future electricity systems. In this regard, end-users are expected to become important actors in sustainable energy management [2] [4] [11].

Smart grids development has resulted in various new energy-related products and services, such as smart meters, smart appliances, micro-generators, storage systems, and energy monitoring and control systems [12]. However, information about the implementation and use of smart energy products and services in smart grid pilots is lacking.

With this study we would therefore like to collect more information from the field regarding the development and implementation smart grid pilots and related products and services.

The main research questions of this study are therefore: (1) How have some typical residential smart grid pilots in the Netherlands been set up? (2) Which stakeholders are involved in these pilots in the year 2014? (3) What are their views and perceptions with regards to the development and performance of residential smart grids? and (4) What do these stakeholders think about products and services that may support an active participation of end-users in a smart energy home?

We have chosen to explore these questions because smart energy products and services are currently being implemented in residential smart grid initiatives, with the expectation that it will support households to improve their energy efficiency, contribute to a more sustainable energy production, and take part in the management of the electricity system [12] [13].

With regards to these products and services, evaluative reports on smart grid developments have highlighted the importance of products and services that meet end-users' needs [4] [7]. We therefore assume that in addition to the development of technological products, emphasis was placed on how these technologies are adapted and domesticated by end-users.

Whilst the views and perceptions of end-users participating in smart grid initiatives have been the basis for these insights, there are still limited insights and reflection from other stakeholders (e.g. grid operators, smart grid project developers and managers, local energy cooperatives) involved in the development and implementation of these initiatives. This will be significant information because these stakeholders have a major influence on the set-up of new smart grid pilots and the selection of smart energy products used in these pilots. Therefore, insights from stakeholders from residential smart grid initiatives could support future implementation, and could also help to generate ideas for future development of smart grid related products and services that match enduser expectations. It could add to the limited knowledge and experience in practice from smart grid initiatives, which are considered a first step in large-scale implementation of smart grids [4] [8].

To explore our research questions this paper is structured as follows. Section 2 discusses the theoretical and 
methodological part of our research, including a brief description of the smart grid initiatives where the interviewees have been involved in. Next, the outcome of the stakeholder interviews will be presented in Section 3 , followed by discussion and conclusions in Section 4.

\section{Research Method}

\subsection{Methodology}

This research draws upon the theoretical framework of Strategic Niche management (SNM). SNM assumes that promising new sustainable technologies can be promoted by actively shaping technological niches, i.e. protected spaces that allow experimentation with the co-evolution of technology, user practices, and regulatory structures [14] [15]. SNM focuses on processes that are internal to the niche development, and is useful for generating learning about needs, technology imperfections and strategies to overcome these [15] [16].

SNM has identified three interrelated processes that are important for the successful development of innovations. These include: articulation of expectations and visions, building of social networks, learning processes [15] [17] [18].

Articulation of expectations and visions, relate to how niches are presented to the public and whether they live up to the promises they make about performance and effectiveness. Expectations provide direction to the technology development, influence design choices, and attract resources as well as new actors. It ensures that outsiders are not excluded from the transition experiment [15].

Building of social networks focuses on the composition of the network and alignment of the actors within it in order to assess their influence on the development of the niche [19]. This process is considered successful when the network is broad, including complementary technologies and infrastructure, and a wide range of representative actors or potential adopters [20] [21].

Learning processes is considered an important issue with regards to the introduction of new technologies. Learning from stakeholders in practice facilitates adjustments in technology and social embedding to increase chances on successful diffusion [15].

Learning processes involve "First-order” and “second-order” learning. "First-order” learning involves lessons about projects and experiences and improving performance.

Second-order learning emphasizes that learning for innovations should extend from technology development to testing actual changes in user practices [15] [22].

Smart grid initiatives, which aim to facilitate sustainable transition to a low carbon electricity regime, qualify as a "niche", and hence can be analyzed using SNM [23].

With regards to smart grids development, the first process in the SNM framework, articulation of expectations and visions has been applied to analyze practices and perceptions of smart grid stakeholders on including users in smart grids experiments in the Netherlands [23].

In this study, we will explore and evaluate building of social networks and learning processes in residential smart grids.

\subsection{Study Design}

The Netherlands was chosen as a location for this research since it provides a growing number of smart grid pilot and demonstration projects.

This study used a qualitative approach and is explorative in nature. It is based on semi-structured face-to-face interviews with nine stakeholders involved in the set-up and implementation of five different Dutch residential smart grid pilot projects (see Table 1). The semi-structured interviews were used because smart grids are still are the early developmental stages, hence the need to get more insights from stakeholders involved in the development. The open and informal style of semi-structured interviews supported the respondents to express their views and opinions in their own terms, while also having the flexibility to provide more details when required. It also allowed the drafting of topics that served as a guideline in exploring the views of the stakeholders.

From the about 30 smart grid pilot projects taking place in the Netherlands in 2014 [10], we selected those pilot projects that incorporate social (user aspects) in their implementation, and have implemented almost the same kind of products and services. Another important consideration in selecting these pilot projects was the ease of getting access to the stakeholders, and the willingness of the stakeholders to participate in the interviews. 
Table 1. List of stakeholders interviewed.

\begin{tabular}{lll}
\hline Stakeholder & Role of Stakeholder & Project \\
\hline 1. Consultant & Project management/Energy consultancy & PowerMatching City I and II Groningen \\
2. Project leader & Project management/Energy consultancy & PowerMatching City I and II Groningen \\
3. Project developer & Project management & PowerMatching City I and II Groningen \\
4. Participant & End-user & PowerMatching City I and II Groningen \\
5. Reseacher/developer & Grid operator & Your Energy Moment Breda and Zwolle \\
6. Technical project leader & Project management & Returns for Everybody Amersfoort and Utrecht \\
7. Project coordinator & Local energy cooperative & Cloud Power Texel \\
8. Project leader & Local energy cooperative & Smart Grids Lochem \\
9. Project manager & Grid operator & Smart Grids Lochem \\
\hline
\end{tabular}

The stakeholder selection process started with the consultation of known experts in the field of smart grids. Further stakeholders were found using "snow-balling” as a method. This resulted in about twenty (20) stakeholders from eight smart grid projects in the Netherlands, who were subsequently contacted by phone to take part in the interviews. In the end, nine stakeholders, from five different projects agreed to take part in the interviews. The stakeholders interviewed in this study $(n=9)$ can be considered to be statistically low. This is due to the fact that there are currently not a lot of people working in the area of smart grids development at the residential areas. Also, smart grids are not commercially installed or implemented yet. Therefore, we consider the sample size, which represents about 50 percent of the smart grid stakeholders, as being quite representative.

Emails were thereafter sent to the respondents to provide more details about the objectives of the study and to schedule appointments for the interviews. The interviews were subsequently conducted individually with the stakeholders, at the locations of the pilot projects and consisted mainly of open-ended questions. The interviews took place between May and September 2014, and lasted between 1 and 1.5 hours.

The five smart grid pilot projects selected included:

1) The "PowerMatching City" project (phases I and II) in Groningen;

2) "Your Energy Moment” projects in Breda and Zwolle;

3) “Cloud Power Texel” project in Texel;

4) "Returns for Everybody” projects in Amersfoort and Utrecht;

5) "Smart Grids Lochem” project in Lochem.

The research in each of the pilot projects is different in terms of the technologies, involvement of end-users and research questions and approaches. However, the aim of this study is however not to compare these projects, but to gather insights from a broader range of stakeholders involved in the development and implementation of residential smart grid initiatives.

The selected smart grid pilot projects are described in more details below. Table 2 provides a summary of the selected projects and Figure 1 shows the locations of the various projects in the Netherlands.

\subsubsection{PowerMatching City I and II in Groningen}

This smart grid pilot project is one of the first projects where smart energy technologies were implemented in homes connected through a smart grid [24] [25]. DNV GL (a Dutch Energy Consultancy company), together with five other project partners (Enexis, Essent, Gas union, ICT automation, TNO research institute) and three knowledge institutes (Hanze polytechnic Groningen, Delft University of Technology, Eindhoven University of Technology), run the project. The project focused on attaining optimum capacity management in a smart grid, and matching energy services with the demands and wishes of end-users [26].

The project was carried out in two phases. Phase one started in 2007 with the realization of a local smart grid with 22 homes. An additional 18 homes were added in 2011 to bring the total number of homes to 40 . The homes were equipped with a micro-cogeneration unit, a hybrid heat pump and hot water tanks, smart appliances such as smart dishwashers and washing machines, and in-home displays (Energy monitor). Also, the homes generated energy through solar photovoltaics installed on their roofs and the roof of other partners. An agentbased algorithm called the 'Power Matcher' manages the energy flows in the local smart grid. This controls the 
Table 2. Summary of the smart grid pilot projects included.

\begin{tabular}{|c|c|c|c|c|}
\hline Project & Technologies used & $\begin{array}{l}\text { Number of } \\
\text { homes }\end{array}$ & Timeline & Stakeholders \\
\hline $\begin{array}{l}\text { 1) PowerMatching City } \\
\text { I and II Groningen }\end{array}$ & $\begin{array}{l}\text { Electric vehicles, hybrid heat pumps, } \\
\text { in-home energy displays, } \\
\text { PowerMatcher software, photovoltaic } \\
\text { systems, smart meters and appliances } \\
\text { (washing machine, freezer, } \\
\text { dishwasher), smart thermostats, } \\
\text { micro-combined heat and power } \\
\text { (CHP) systems, wind turbine, mini } \\
\text { gas turbines, electricity storage, } \\
\text { automated meter reading }\end{array}$ & 40 & 2007-2015 & $\begin{array}{l}\text { Grid operator, knowledge } \\
\text { institutes, energy consulting } \\
\text { company, ICT software company, } \\
\text { gas company, service provider, } \\
\text { energy supplier, individual } \\
\text { end-users }\end{array}$ \\
\hline $\begin{array}{l}\text { 2,3) Your Energy } \\
\text { Moment Zwolle and } \\
\text { Breda }\end{array}$ & $\begin{array}{l}\text { Smart grid, photovoltaic systems, } \\
\text { smart appliances (washing machines, } \\
\text { dryers) }\end{array}$ & 250 & 2012-2015 & $\begin{array}{l}\text { Grid operator, knowledge } \\
\text { institute, product and service } \\
\text { suppliers, housing company, } \\
\text { energy supplier, local energy } \\
\text { cooperative (end-users) }\end{array}$ \\
\hline $\begin{array}{l}\text { 4,5) Returns for } \\
\text { Everybody Amersfoort } \\
\text { and Utrecht }\end{array}$ & $\begin{array}{l}\text { Heat pumps, electric vehicles, } \\
\text { in-home electricity storage }\end{array}$ & 200 & 2012-2015 & $\begin{array}{l}\text { Grid operator, knowledge } \\
\text { institutes, product and service } \\
\text { suppliers, sustainable energy } \\
\text { supplier, local energy cooperative } \\
\text { (end-users) }\end{array}$ \\
\hline 6) Cloud Power Texel & $\begin{array}{l}\text { Smart meters, cloud power (energy } \\
\text { matching software), wind turbines, } \\
\text { photovoltaic systems }\end{array}$ & 300 & 2012-2014 & $\begin{array}{l}\text { Grid operator, project developer, } \\
\text { ICT company, product and service } \\
\text { supplier, sustainable energy } \\
\text { supplier, local energy cooperative } \\
\text { (end-users) }\end{array}$ \\
\hline 7) Smart Grids Lochem & $\begin{array}{l}\text { Photovoltaic systems, electric } \\
\text { vehicles, smart meters }\end{array}$ & 130 & 2012-2015 & $\begin{array}{l}\text { Grid operator, knowledge } \\
\text { institute, product and service } \\
\text { suppliers, energy supplier, } \\
\text { sustainable energy supplier, local } \\
\text { energy cooperative (end-users) }\end{array}$ \\
\hline
\end{tabular}

switching on and off of smart appliances, heat pumps, and micro-cogeneration units based on market mechanisms and user settings.

PowerMatching City phase one was finalized in 2011, while phase two finished in 2014. A detailed of PowerMatching City is described by [24].

\subsubsection{Your Energy Moment in Zwolle and Breda}

This smart grid pilot project [27] is run by Enexis (a Dutch major utility company). Other partners in the project include housing corporation SWZ (Samenwerkende Woon-en Zorgvoorzieningen in Dutch), Dong Energy (energy supplier), Consultants to Government and Industry (CGI) Logica (Information and Communication Technology (ICT) Company), Flexicontrol (product and service supplier) and a knowledge institute (Eindhoven University of Technology). The Your Energy Moment project focuses on acquiring more experience with technical, economic and social options for creating flexibility and increased sustainability in the energy consumption of consumers, in a realistic and practical environment. The participants in the pilot project also receive dynamic prices. The objective is to investigate if households are able and willing to adapt their demand to times on which supply is abundant.

It consists of 250 homes equipped with a smart grid, solar panels, home energy management systems, smart washing machines and dryers. The pilot in Zwolle started in 2012 and consists of 100 homes. The pilot in Breda started in 2013 and consists of 150 homes. Both projects of Your Energy Moment will run till 2015.

\subsubsection{Returns for Everybody in Amersfoort and Utrecht}

This smart grid pilot project, known as "Rendement Voor Iedereen” in Dutch, is sponsored by the province of Utrecht, and the municipalities of Utrecht and Amersfoort [28]. Other partners involved in this project include Stedin (grid operator), DNV GL, Capgemini (product and service supplier), knowledge institutes (Universities of Groningen and Utrecht, Utrecht polytechnic), Ecofys (renewable energy supplier), Lomboxnet (ICT company), 


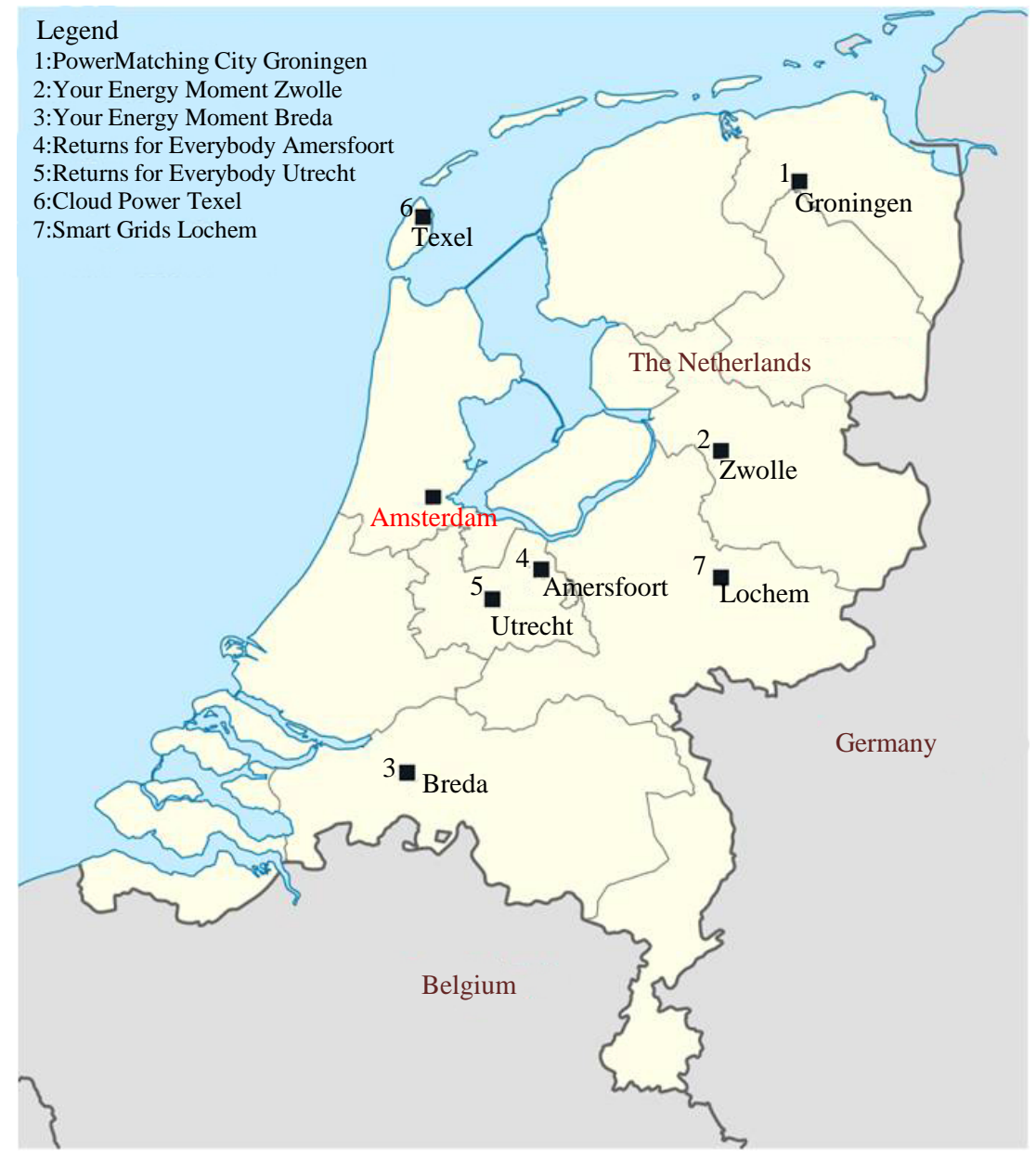

Figure 1. Location of smart grid pilots in the Netherlands.

Eemflow (local energy cooperative), Icasus (citizen's initiative), and innovation taskforce Utrecht region [28]. Returns for everybody develops and tests various new smart grid services related to the future electricity network. It consists of 100 homes in Amersfoort and Utrecht, where eight new smart grid service concepts are being developed and tested. These services focus on energy savings and optimal use of locally produced solar energy. The homes consist of an energy management system, solar photovoltaics, and smart meters. Both pilots of Returns for Everybody were carried out between 2012 and 2014.

\subsubsection{Cloud Power Texel in Texel}

Cloud Power Texel is a bottom-up experiment initiated by a community of energy users that individually and collectively try to make their energy use more sustainable and be energy independent with renewable energy sources [23]. It was started by TexelEnergie (a local energy cooperative with more than 3000 members [29] and two other partners, Alliander (grid operator) and Capgemini (product and service supplier). The Cloud Power Texel smart grid pilot project explores how a community can provide its own energy needs, by stimulating energy efficiency and behavioural change. The project was carried out in Texel (an island in the Netherlands) and included 300 homes [30]. Technologies implemented in this project include smart meters, an in-home energy display called "Kiek" that gives insight in energy use and generation, home energy management systems and distributed generation units connected to the grid. The Cloud Power Texel project was carried out between 2012 and 2014.

\subsubsection{Smart Grids Lochem in Lochem}

Smart Grids Lochem is a bottom-up initiative set up by a local energy cooperative, LochemEnergie. Other part- 
ners involved in this smart grid pilot project include Locamation and Eaton industries (product and service suppliers), Alliander (grid operator) and University of Twente. This project takes place in an existing residential area, where participants (members of the local energy cooperative) are equipped with a smart meter called "Mpare", solar photovoltaics on their own roofs and roofs of other public buildings [31]. Smart Grids Lochem explores how to involve and stimulate residential end-users to reduce their energy consumption, make use of renewable energy, and help in aligning energy demand and supply. Also, experimenting with electric vehicle (load technics and behaviour) is part of this project. The Smart Grids Lochem project started in 2011 and will be completed in 2015.

\subsection{Interviews}

The questions for the interviews were grouped into three main themes. These include:

1) Stakeholders' involvement in the project's preparation phase;

2) Stakeholders' perception of products and services for smart grid pilots;

3) Requirements for future products and service development.

\subsubsection{Theme 1. Stakeholders' Involvement in the Project's Preparation Phase}

The questions under this theme mainly focused on identification of stakeholders involved in the development of residential smart grid pilot projects:

- $\quad$ their respective roles in the realization of the projects;

- $\quad$ the estimated costs of setting up the projects and the funding sources;

- $\quad$ the major expenditures involved;

- $\quad$ the stakeholder considered the most important in the realization of residential smart grid projects.

\subsubsection{Theme 2. Stakeholders' Perception of Products and Services for Smart Grid Pilots}

The questions under this theme mainly focused on exploring current products and services offered in the projects, and the perception of smart grid stakeholders on:

- $\quad$ the current approaches used in developing these products and services;

- $\quad$ the performance of smart grid products and services;

- $\quad$ the role of various stakeholders (including end-users) in the development process.

\subsubsection{Theme 3. Requirements for Future Products and Service Development}

The questions under this theme mainly focused on exploring stakeholders' views on potential smart grid products and services:

- $\quad$ the functions these products and services are expected to perform;

- $\quad$ current and future demands with regards to product and service development for residential smart grids.

\subsection{Data Analysis}

The data gathered from the interviews was analyzed manually. First the interviews were digitally recorded using a voice recorder and were transcribed verbatim as a word document. Then, the main views and perspectives were identified and discussed with the authors. After consensus, these main views and perspectives became the basis for further analysis.

Validation of the information by respondents is an important aspect of ensuring the accuracy of data collected through unstructured interviews [32]. In order to increase completeness and reduce inconsistencies, the results of this study were checked by two of the respondents (a grid operator and a project manager of a local energy cooperative). These respondents provided useful comments to refine the results.

\section{Results}

This study explored the views and perceptions of nine stakeholders involved in residential smart grid pilot projects, with regards to the implementation of these projects and the development and performance of products and services. The following section presents the findings from the interviews. An overview of the findings is presented in Table 3. 


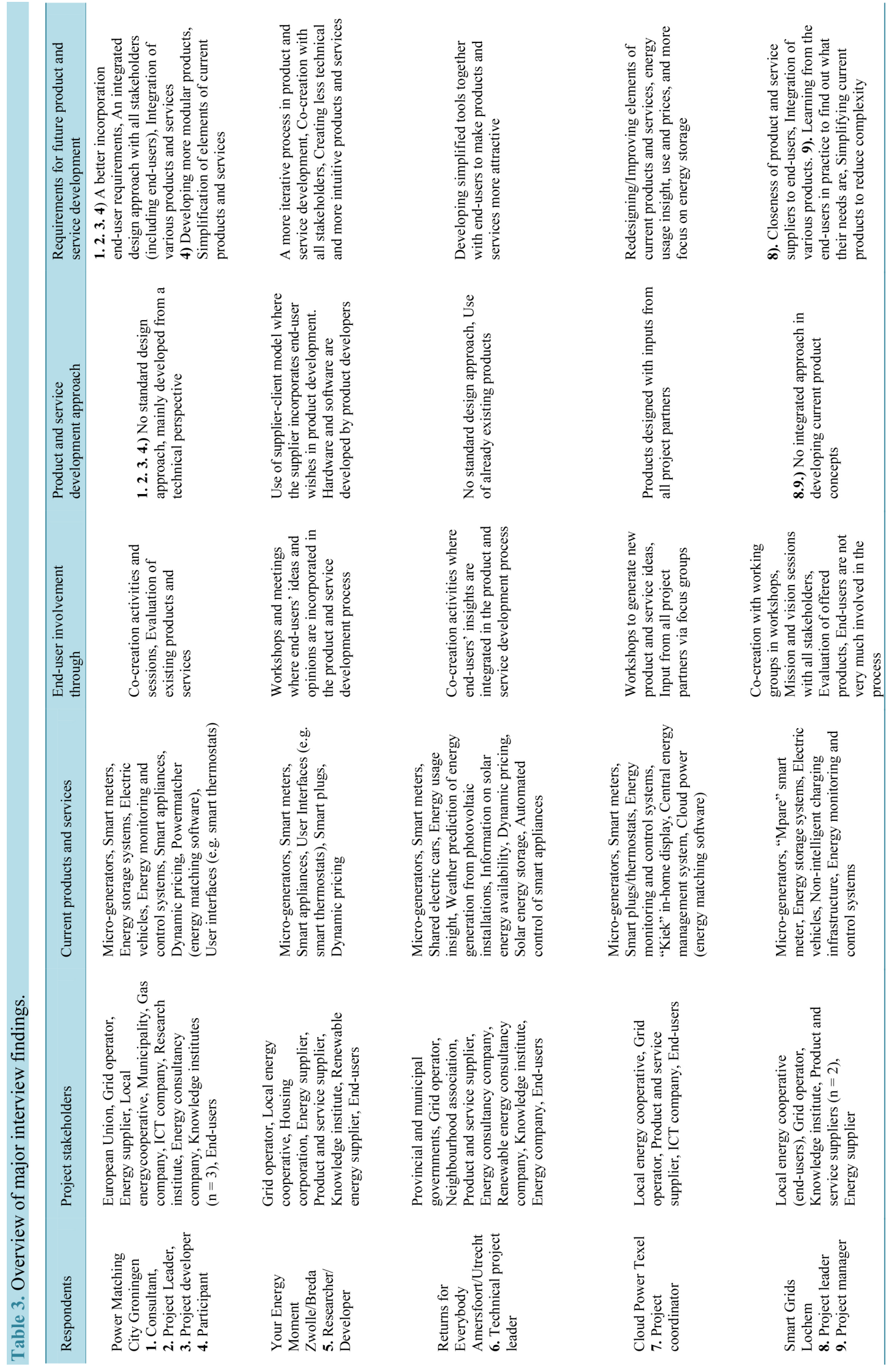




\subsection{Theme 1. Stakeholders' Involvement in the Project's Preparation Phase}

\subsubsection{Setup Project}

From the five smart grid pilot projects explored, one project (PowerMatching City) was set-up as a European Union project; one project (Your Energy Moment) was set-up by a grid operator (Enexis); two projects (Cloud Power Texel and Smart Grids Lochem) were set-up by local energy cooperatives (TexelEnergie and Loche$\mathrm{mEnergie)}$ and a grid operator (Alliander), and one project (Returns for Everybody) was initiated by the provincial and municipal governments. PowerMatching City was carried out mainly with subsidy from the European Union. The other four projects were partly funded by subsidies from the national, provincial and municipal governments and the various partners involved in the projects, like the grid operators (such as Alliander and Enexis), local energy cooperatives (such as LochemEnergie and TexelEnergie) and energy suppliers (such as Essent and Dong Energy).

The major costs in these projects were similar (ranging from 5 to 10 million euros) and were mostly spent on the procurement and installation of equipment such as smart meters and appliances, development of the needed knowledge and infrastructure such as smart charging stations for electric vehicles, services on storage, deployment of software installations, and workshops and information dissemination to encourage end-user participation.

\subsubsection{Involvement of Stakeholders}

In general, the following stakeholders were involved in the development and implementation of residential smart grid pilot projects:

- $\quad$ European Union (in one project)

- $\quad$ National, provincial and municipal governments (in two projects)

- $\quad$ Grid operators (in all five projects)

- $\quad$ Energy suppliers (in five projects)

- $\quad$ End-users participating homes (in all five projects)

- $\quad$ Product and service suppliers (in four projects)

- Information and Communication Technology (ICT) companies (in two projects)

- Knowledge institutes (in four projects)

- $\quad$ Local energy cooperatives (in four projects)

The European Union provided the funding for large-scale pilot projects, such as the PowerMatching City project. The national, provincial and municipal governments supported the funding of smaller-scale projects, such as Smart Grids Lochem, Cloud Power Texel, and Returns for Everybody.

In all projects, the grid operators were mainly involved to explore methods to reduce peak load in the electricity grid. They also provided dynamic pricing that helped to influence end-user behaviour in using energy at certain preferred times (such as when there is increased renewable energy generation or during periods of lower peak in the electricity network). The grid operators Alliander and Enexis were involved in all five projects.

The energy suppliers produced and delivered gas, electricity, heat and energy services to the participating homes in these smart grid pilot projects. The participating homes (residential end-users) supported the provision of flexibility in energy use by adjusting and adapting their energy usage behaviour, in response to the flexible pricing provided by the grid operators. The ICT companies were responsible for the development of software that enabled all the components of the energy system to communicate in a smart way. The product and service suppliers were responsible for producing and supplying various hardware and software, such as smart meters, energy usage insights and energy management. The various knowledge institutes supported the development of knowledge and various software needed to match energy supply and demand. Their input also focused on studying behavioural issues concerning residential end-users, and the interaction of end-users with various technologies. The local energy cooperatives served as a platform for end-users to organize themselves in building and managing a sustainable energy system.

The local energy cooperatives were involved in the set-up of four projects (Returns for Everybody, Cloud Power Texel, Smart Grids Lochem and Your Energy Moment), while the grid operators (also known as Distribution System Operators-DSO's) were involved in the set-up of all projects. The product and service suppliers were involved in the set-up of three projects (Smart Grids Lochem, Returns for Everybody and Your Energy Moment). 
All respondents considered the DSO's, energy suppliers and end-users (individually or via local energy cooperatives) as the current major stakeholders in residential smart grid projects. The results also showed that three projects were initiated through local energy cooperatives, but the DSO’s played a leading role in their development and implementation. This was evident by their participation in all projects. According to the coordinator Cloud Power Texel, "the project in Texel was initiated by Texel Energie; Alliander came in afterwards to use it as a try-out for smart meters in homes". This was also the case with Smart Grids Lochem, where Lochem Energy cooperative initiated the project and asked Alliander and other partners to join. Together they developed a plan and proposal that was submitted to the National government for funding.

Explaining the presence of the grid operators in all the projects, a principal consultant from Power Matching City said that, "the grid operators are struggling with the fact that there are quite a number of new technologies that all require additional capacity of the grid, therefore, they are looking for new methods to reduce peak load in the grid and avoid long-term grid costs, hence their active participation in smart grid projects". He also stated that the expected growth in electric vehicles would have an enormous impact on the grid. Therefore, the grid operators are exploring new ways to deliver peak electricity capacity at every point in time in the transition to smart grids.

The interviews revealed that the energy supplier was present in all projects in order to get the best value out the demand response provided by end-users. Demand response implies alterations in end-users' electricity usage in reaction to supply conditions [4].

However, all respondents acknowledged that the involvement of end-users is an important aspect in smart grids implementation, since they are as essential part of the flexibility required to balance the grid. The project manager of Smart Grids Lochem summed it up by saying that, "The end-user is the starting point, therefore, it is important to think about what the energy system should be, in order to fulfil the needs of the end-users”.

\subsection{Theme 2. Stakeholders' Perception of Products and Services for Smart Grid Pilots}

Although the five projects in this study are different in terms of how the smart energy system implemented in the projects look like, the products and services being used are similar for all projects. In all projects, microgenerators, such as solar photovoltaics, were the major renewable energy technologies used. Energy monitoring and control systems, smart meters and supporting devices (e.g. the "Mpare" device used in Smart Grids Lochem), smart appliances and plugs were also deployed in all projects.

In the projects Cloud Power Texel, Your Energy Moment and Returns for Everybody, dynamic pricing featured prominently. This involved the use of varying energy prices to stimulate end-users to shift energy use to off-peak periods to reduce the load on the electricity network.

Power Matching City and Smart Grids Lochem were the only two projects where energy storage systems were deployed. These were deployed by means of hot water storage, storage heaters and batteries of electric vehicles. This enabled energy use at different times, thereby supporting flexibility in energy use.

With regards to how current products and services are developed, most respondents (8 out of 9) indicated that most of the products and services offered in the pilots, including those that end-users are supposed to interact with, are developed from the perspectives of the technical partners involved in these projects. They stated that current available products and services are still too technical, and this is a problem for the end-users, as they do not always understand how they function. According to the developer from Your Energy Moment, end-users in some of the homes described their in-home display as "another product developed by techies for techies" and "current products are way too technical and complex, not very intuitive and not inspired by end-user insights". It is better to start developing these products with the end-users from the beginning, this will support people to better communicate and interact with the energy system".

The consultant from Power Matching City expressed his opinion as follows: "These energy products and services are mostly developed from an electrical engineering and digital technology perspective. This is also partly the reason why large-scale roll out of smart meters has not been achieved yet. Although the European Union has fixed 2018 as the deadline for large-scale roll out of smart meters, this has not been achieved yet due to the fact that the smart meter was developed purely from a technical perspective". He further stated that current products are services are developed from different perspectives, and there is currently a lack of standardized products, and also no interoperability between existing products and services. The project manager of Smart Grids Lochem stated that the different partners, who want to use the project as a testing ground, independently developed most of the products and services implemented in the pilot project. 4 out of the 9 respondents also stated 
that these product and service suppliers are usually not partners of the project consortium and are therefore not involved in the day-to-day decision-making processes in the project. Their interaction with the participating end-users was also quite limited.

According to 7 out of 9 respondents, the development process of most of the offered products and services (such as smart meters, in-home displays and digital applications) involved the active participation of end-users and other project partners through various workshops and co-creation activities.

The participating end-user in the PowerMatching City project expressed satisfaction with the smart energy system, since it helped to provide insight in household energy behaviour, and a means to play an active role in their energy usage. He, however, asserted that there is limited interaction between the end-user and the energy system. This, in his opinion, is mainly due to the fact that most of the offered products work in the background. He stated that, "most of the current products and services work in the background. We want to get more involved with the technology, and have more insights about the workings of technology, and also be aware of what is happening in our homes. It is important to monitor and manually control the smart appliances”.

Two respondents shared related views with regards to the PowerMatcher software that balances energy demand and supply. In their opinion, products such as the PowerMatcher software that operates in the background needs to be simplified because it is difficult to figure out how it functions and allocates energy to the various in-home appliances.

The project coordinator of Cloud Power Texel said that elements of current products and services need to be improved, because they are way too complex and over-dimensional and not inspired by end-user insights. For this reason, a simplified and improved version of the "Toon" display from the energy company Eneco was developed and implemented in the project. This they called "Kiek", an in-home display that gives insight into energy usage.

\subsection{Theme 3. Requirements for Future Product and Service Development}

The respondents revealed that various products and services would be required to support an active participation of end-users in the future energy system. According to more than half of the respondents $(n=5)$, these include mainly products and services that:

- $\quad$ provide visual insight to end-users with regards to their current state of energy generation, usage patterns of household devices and prices, such as digital applications, graphical user interfaces, games, feedback and energy forecast

- $\quad$ promote dynamic pricing

- $\quad$ support the use of smart appliances (for example, manual programming of washing machine when the sun is shining)

- $\quad$ enable end-users to compare their energy usage with others

According to the project manager of Smart Grids Lochem, most of these products and services could influence end-user behaviour; to use energy more efficiently in households, provide more control over their energy generation and use, and ensure optimal use of renewable energy produced within the community (for example facilitate energy sharing).

In the views of the consultant from Power Matching City, there are currently limited services that support end-users in the usage of various technological products, such as smart meters. Therefore, new user interfaces or remote controls for new services will be needed to support end-users in using technologies such as smart meters.

The technical project leader of Returns for Everybody said that a big challenge in future product and service development is to make simpler, more interpretable and understandable versions of already existing tools such as user interfaces.

This, in her opinion, could support active involvement of people with little technical experience that want to be active with energy. She also stated that different end-user segments should have tools that match their knowledge and experiences. For instance, the Ambassador for their project in Amersfoort who is quite oldfashioned does not own a smart phone, while most of the tools for energy usage insight are connected smart phones. This ambassador usually prints out the energy display data to ask for an explanation of their meaning. She further stated that there are two categories of users, those with technical know-how and those without. It is therefore important keep them involved and attracted to products.

For the participant in the Power Matching City project, tools and means to influence or control the usage of solar photovoltaics (such as weather forecasts) should be provided to the users themselves so they can balance 
and regulate their usage of renewable energy instead of automatic balancing done by the Power Matcher software.

With regards to the requirements that should be met for developing future products and services, 6 out of 9 respondents stated that end-users should be the starting point in the development process. Although end-users currently take part in various co-creation workshops, they are mostly aimed at evaluating and improving products and services offered in the projects. According to the project manager from Smart Grids Lochem, "end-users mainly help to evaluate the use of the products, but not very much in product and service development. This is actually a problem".

From an end-user's point of view, the residential end-user in the Power Matching City project stated that end-users want to be more involved in future product and service development process, contributing their views and insights. This, he said, will help to create products that can be easily understood and communicated with. He stated, "There is a need for end-users to define what they want, and also the need for product and service developers to be close to the end-users, and know what their wishes are. This makes new product features accessible and understandable”. He further stated that product and service functionalities that give end-users more control over their energy generation and use options will help to improve energy efficiency and increase local renewable energy generation.

The consultant from Power Matching City was of the opinion that a lot of technology-based products and services do not always consider the implication for the end-users who are going to use them. He advocated that product and service developers should look from the perspective of what end-users need, as this proves a better approach than trying to push technology.

The developer from Your Energy Moment suggested the use of an iterative design approach, and starting with small steps (e.g. creating simple and less complicated products and services) in product and service development.

\section{Discussion and Conclusions}

In this section we will reflect on the main research questions of this study, which are: (1) how have some typical residential smart grid pilots in the Netherlands been set up? (2) Which stakeholders are involved in these pilots in the year 2014? (3) What are their views and perceptions with regards to the development and performance of residential smart grids? And (4) what do these stakeholders think about products and services that may support an active participation of end-users in a smart energy home?

Using insights from the Strategic Niche Management (SNM) process of building of social networks and learning in innovations, our study shows that the European Union, national, provincial and municipal governments, grid operators, energy suppliers, household end-users, product and service suppliers, Information and Communication Technology (ICT) companies, knowledge institutes and local energy cooperatives are currently involved in residential smart grid pilots. The grid operators currently play a leading role in the implementation of these projects.

Regarding the development and performance of residential smart grids, insights from our study show that a technology-push approach currently exists in smart grids products and services development, with a dominance of the perspectives of the technical partners involved in the projects. This has resulted mostly in functionally attractive, but rather technically complex products and services that end-users do not always easily understand and interact with. Also, there is a lack of integrated approach in developing products and services development.

A general opinion among the stakeholders is that a better incorporation of user perspectives, especially at the early stages, will be required in order develop products and services that support an active participation of endusers in a smart energy home.

It can be concluded that learning processes in residential smart grids is still very much focused on the developing and testing of various smart grid technologies, but to a lesser extent on how to "co-shape" technology innovations in smart grids with potential users from an early stage. We therefore recommend that a better alignment of technology development and the user environment would be required for future developments leading to better smart grid products and services.

In more detail, we can conclude from the interviews that currently the main stakeholders involved in the setting up of residential smart grid initiatives are the government, grid operators, energy suppliers, various product and service suppliers, end-users (as an energy cooperative or individual households). However, the grid operators currently play a leading role. This was expected, given that they need to explore new ways of effectively 
accommodating various renewables and decentralized energy generation in their grids in order to optimize the entire energy system and reduce peak load in the electricity network [8]. However, a general perception held by almost all respondents was that end-users are key for a successful development and implementation. Despite this recognition and involvement of end-users in various co-creation workshops, almost all respondents revealed that current products and services offered in most of the projects, are very attractive, but appear to be too technically-complex for most end-users. We assume that these complexities result from the way smart grid initiatives are currently set-up, and how the products and services have been developed, namely with dominantly technical approaches originating from the fields of electrical engineering, power systems and digital technologies. The perspectives of the technical partners involved in residential smart grid projects, such as grid operators, energy suppliers and product and service suppliers, were mainly the starting point of the development of these products and services. These products and services include energy monitoring and control systems, in-home displays, energy generation and usage information, and home energy management systems. Some of these products and services include the provision of very detailed graphical and technical information which is often not understood by end-users.

A study of how users experience and interact with an Energy Management System (EMS) concludes that in order to change people's behavior to shift their electricity consumption to match the local supply, it is important that designers implement the system in a way that user interaction is not perceived as being cumbersome [33]. The study further suggested that the EMS interface should have an intuitive design that enables users to directly use the system without having a good deal of prior knowledge, as certain users would prefer simple interfaces with limited information, while others would require comprehensive insights in their electricity production and consumption.

This implies that the way users and the energy system interact is an important aspect of user involvement as active participants in balancing energy demand and supply [23]. Therefore, technical complexity of products and services offered in residential smart grids could affect how end-users interact with these technologies. We therefore assume that this could further limit changes in energy behavior by end-users, required to balance energy demand and supply in a smart grid.

The development of simplified, less cumbersome products and services that end-users can easily use and interact with could support their role as energy citizens and active participants in a smart grid [34]-[36]. This simplification could support a better end-user engagement with smart grid technologies, adjustments in behavior to reduce energy consumption, and a better use of renewable energy technologies [33] [37] [38].

This study also highlights that already existing products and services are usually procured by various product and service suppliers and used in these projects, with end-users mainly evaluating the functioning and performance of these products and services, and providing feedback on what should be improved. Most often, the functioning of these technologies is not very much understood by end-users. Product and service development appears to be mainly driven by commercial desire for technical innovation, and thus an integrated approach in product and service development is now lacking.

We therefore assume that simple "plug and play" tools and devices that are manually controlled and provide limited and more understandable information, could support end-users to better manage and control their energy usage and generation options, than the advanced, automated technical solutions that mainly work in the background, with limited end-user interaction. Therefore, in order to create improved, more simplified, intuitive and user-friendlier smart grid products and services, a User-Centred Approach (UCD) [39] should be employed.

Though user perspectives are currently incorporated in developing smart grid products and services, their involvement is still very much limited to the evaluation of the performance of pre-determined products and services offered in residential smart grids. This makes them mere passive recipients of pre-determined solutions.

A better alignment of technology development and the user environment could be required in future developments. This will help to "co-shape" technology innovations in smart grids with potential users from an early stage.

A technology-push approach and a lack of integrated approach in the development of smart grid products and services could limit the adaptations of these technologies by end-users, and the success of future implementation of smart grids.

Hence, based on the findings of this study, we propose a more active involvement of end-users and a better cooperation with all the relevant stakeholders in smart grid product and service development process. This will help to create products and services that better meet end-users' needs in a smart grid context. 
This study provides indicative rather than conclusive findings due to the limited number of respondents per project $(n=9)$ and projects explored $(n=5)$, and the limited comparability between the projects. For instance, one of the projects in this study (Power Matching City I) started up as a technical pilot that focused on exploring the technological feasibility of integrating various renewable energy sources. This is in contrast to the other four projects that were more bottom-up and were initiated by end-users

However, the value of this study, despite a having a limited statistics, is that it is one of the first studies that focuses on exploring the views of a broad range of stakeholders involved in residential smart grid projects.

Though governments (both national and local governments), energy suppliers and academics are important stakeholders in smart grids development, the views of these specific stakeholders were not explicitly explored in-depth in this study. To provide deeper insights in policy directions for future smart grids development it is therefore recommended to execute more studies in the future regarding governmental influences in this field.

\section{Acknowledgements}

This work is part of the research programme of University Campus Fryslân (UCF), which is financed by the Province of Fryslân. The authors thankfully acknowledge all the respondents that participated in the interviews.

\section{References}

[1] International Energy Agency (IEA) (2012) World Energy Outlook. IEA, Paris.

[2] Nye, M., Whitmarsh, L. and Foxon, T. (2010) Socio Psychological Perspectives on the Active Roles of Domestic Actors in Transition to a Lower Carbon Electricity Economy. Environment and Planning A, 42, 697-714.

[3] EnergieTrends (2014) A Publication of Netherlands Energy Research Center, Energie-Nederland and Netbeheer Nederland. http://www.energietrends.info

[4] International Energy Agency (IEA) (2011) Technology Roadmaps: Smart Grids. IEA, Paris.

[5] Executive Office (2011) A Policy Framework for the 21st Century Grid: Enabling Our Secure Energy Future. Executive Office of the President of the United States, Washington DC.

[6] Netherlands Ministry of Economic Affairs (2010) Op weg naar intelligent netten in Nederland. Discussion Document of the Task Force Smart Grids. The Hague. (In Dutch) https://www.rijksoverheid.nl/documenten/rapporten/2011/05/20/op-weg-naar-intelligente-netten-in-nederland

[7] Giordano, V., Gangale, F., Fulli, G. and Sánchez Jiménez, M. (2011) Smart Grid Projects in Europe: Lessons Learned and Current Developments. Joint Research Centre of the European Commission, Institute for Energy, Petten.

[8] Gangale, F., Mengolini, A. and Onyeji, I. (2013) Consumer Engagement: An Insight from Smart Grid Projects in Europe. Energy Policy, 60, 621-628. http://dx.doi.org/10.1016/j.enpol.2013.05.031

[9] European Commission's Joint Research Centre (2014) Smart Grids Project Outlook. European Union.

[10] Netbeheer Nederland (2014). http://www.netbeheernederland.nl/smartgrids/

[11] Fang, X., Misra, S., Xue, G. and Yang, D. (2012) Smart Grid—The New and Improved Power Grid: A Survey. Article in IEEE Communications and AMP Tutorials.

[12] Geelen, D., Reinders, A. and Keyson, D. (2013) Empowering the End-User in Smart Grids: Recommendations for the Design of Products and Services. Energy Policy, 61, 151-161. http://dx.doi.org/10.1016/j.enpol.2013.05.107

[13] Gungor, V.C., Sahin, D., Kocak, T., Ergüt, S., Buccella, C., Cecati, C. and Hancke, G.P. (2012) Smart Grids and Smart Homes: Key Players and Pilot Projects. IEEE Industrial Electronics Magazine, 6, 18-34.

[14] Schot, J.W. and Geels, F.W. (2008) Strategic Niche Management and Sustainable Innovation Journeys: Theory, Findings, Research Agenda, and Policy. Technology Analysis and Strategic Management, 20, 537-554. http://dx.doi.org/10.1080/09537320802292651

[15] Hoogma, R., Kemp, R., Schot, J.W. and Truffer, B. (2002) Experimenting for Sustainable Transport. The Approach of Strategic Niche Management. Spon Press, New York.

[16] Van der Laak, W.W.M., Raven, R.P.J.M. and Verbong, G.P.J. (2007) Strategic Niche Management for Biofuels: Analysing Past Experiments for Developing New Biofuels Policies. Energy Policy, 35, 3213-3225. http://dx.doi.org/10.1016/j.enpol.2006.11.009

[17] Kemp, R., Schot, J. and Hoogma, R. (1998) Regime Shifts to Sustainability through Processes of Niche Formation. The Approach of Strategic Niche Management. Technology Analysis and Strategic Management, 10, 175-196. http://dx.doi.org/10.1080/09537329808524310 
[18] Geels, F.W. and Schot, J. (2010) Managing Sustainable Innovation Journeys. In: Grin, J., Rotmans, J. and Schot, J., Eds., Transitions to Sustainable Development. New Directions in the Study of Long Term Transformative Change, Routledge, New York, 80-92.

[19] Raven, R.P.J.M. (2005) Strategic Niche Management for Biomass. PhD Thesis, Eindhoven University of Technology, Eindhoven.

[20] Kemp, R., Rip, A. and Schot, J. (2001) Constructing Transition Paths through the Management of Niches. In: Garud, R. and Karnoe, P., Eds., Path Dependence and Creation, Lawrence Erlbaum, London, 269-299.

[21] Elzen, B., Geels, F.W. and Green, K. (Eds.) (2004) System Innovation and the Transition to Sustainability: Theory, Evidence and Policy. Edward Elgar, Cheltenham.

[22] Coenen, L., Raven, R. and Verbong, G. (2010) Local Niche Experimentation in Energy Transitions: A Theoretical and Empirical Exploration of Proximity Advantages and Disadvantages. Technology in Society, 32, 295-302. http://dx.doi.org/10.1016/j.techsoc.2010.10.006

[23] Verbong, G.P.J., Beemsterboer, S. and Sengers, F. (2012) Smart Grids or Smart Users? Involving Users in Developing a Low Carbon Electricity Economy. Energy Policy, 52, 117-125. http://dx.doi.org/10.1016/j.enpol.2012.05.003

[24] Bliek, F., van den Noort, A., Roossien, B., Kamphuis, R., de Wit, J., van der Velde, J. and Eijgelaar, M. (2010) PowerMatching City, a Living Lab Smart Grid Demonstration. 2010 IEEE PES Innovative Smart Grid Technologies Conference Europe (ISGT Europe), Gothenburg, 11-13 October 2010, 1-8.

[25] Geelen, D., Scheepens, A., Kobus, C.B.A., Obinna, U., Mugge, R., Schoormans, J.P.L. and Reinders, A. (2013) Smart Energy Households' Field Tests in The Netherlands with a Design-Driven Approach. 4th European Innovative Smart Grid Technologies (ISGT) Conference, Lyngby, 6-9 October 2013, 1-5.

[26] Netherlands Ministry of Economic Affairs (2013) PowerMatching City II. https://www.rvo.nl/sites/default/files/2013/09/PowerMatching\%20City\%20II.pdf

[27] Netherlands Ministry of Economic Affairs (2013) Your Energy Moment: Smart Grids with the Consumers. https://www.rvo.nl/sites/default/files/2013/09/Jouw\%20Energie\%20Moment.pdf

[28] Utrecht Sustainability Institute, 2014. http://www.usi.nl/projecten/energie/smart-grid-rendement-voor-iedereen-2/

[29] Netherlands Ministry of Economic Affairs (2013) Cloud Power Texel. https://www.rvo.nl/sites/default/files/Cloud\%20Power\%20Texel.pdf

[30] TexelEnergie, 2015. http://www.texelenergie.nl/texel-slim-zelfvoorzienend/67/

[31] Netherlands Ministry of Economic Affairs (2013) Smart Grids in Sustainable Lochem. https://www.rvo.nl/sites/default/files/2013/09/Intelligent\%20net\%20in\%20duurzaam\%20Lochem\%20UK.pdf

[32] Kumar, R. (2014) Research Methodology: A Step-by-Step Guide for Beginners. 4th Edition, Sage Publications, London.

[33] Kobus, C.B.A., Mugge, R. and Schoormans, J.P.L. (2012) Washing When the Sun Is Shining: How Users Interact with a Household Energy Management System. Ergonomics, 56, 451-462. http://dx.doi.org/10.1080/00140139.2012.721522

[34] Chappells, H. (2003) Re-Conceptualizing Electricity and Water: Institutions, Infrastructures and the Construction of Demand. Lancaster University, Lancaster.

[35] Sauter, R. and Watson, J. (2007) Strategies for the Deployment of Microgeneration: Implications for Social Acceptance. Energy Policy, 35, 2770-2779. http://dx.doi.org/10.1016/j.enpol.2006.12.006

[36] Van Vliet, B., Chappells, H. and Shove, E. (2005) Infrastructures of Consumption: Environmental Innovation in the Utility Industries. Earthscan, London.

[37] Geelen, D., Vos Vlammings, M., Filippidou, F., Van den Noort, A., Van Grootel, M., Moll, H., Reinders, A. and Keyson, D. (2013) An End-User Perspective on Smart Home Energy Systems in the PowerMatching City Demonstration Project. 4th IEEE PES Innovative Smart Grid Technologies Europe (ISGT Europe), Lyngby, 6-9 October 2013, 1-5. http://dx.doi.org/10.1109/isgteurope.2013.6695387

[38] Stern, P.C. (2014) Individual and Household Interactions with Energy Systems: Toward Integrated Understanding. Energy Research and Social Science, 1, 41-48. http://dx.doi.org/10.1016/j.erss.2014.03.003

[39] Wever, R., van Kuijk, J. and Boks, C. (2008) User-Centred Design for Sustainable Behaviour. International Journal of Sustainable Engineering, 1, 9-20. 